\title{
A genome-wide search for Type II diabetes susceptibility genes in Chinese Hans
}

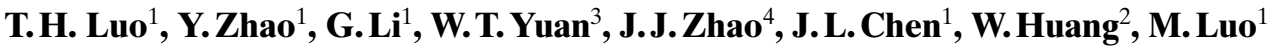 \\ ${ }^{1}$ Shanghai Institute of Endocrinology, Ruijin Hospital, Shanghai Second Medical University, Shanghai, China \\ ${ }^{2}$ Chinese National Human Genome Center at Shanghai, Shangai, China \\ ${ }^{3}$ Centre for Molecular Medicine, Ruijin Hospital, Shanghai Second Medical University, Shanghai, China \\ ${ }^{4}$ Shandong Provincial Hospital, Shanghai, China
}

Abstract

Aims/hypothesis. The aim of the study was to search for Type II (non-insulin-dependent) diabetes mellitus susceptibility genes in a Chinese population.

Methods. A genome-wide scan was carried out using non-parametric linkage analyses. We studied 102 families (478 family members) who were Chinese Hans residing in east and south-east China, including 282 diabetic patients, among them 142 independent affected sibpairs were available for genotyping. A total of 247 fluorescence labelled microsatellite markers, with an average resolution of $15 \mathrm{cM}$, were amplified. GENEHUNTER was used for the non-parametric linkage analyses.

Results. Two loci on chromosome 9 D9S171 and D9S175 showed suggestive evidence for linkage, with an NPL-score of 3.286 and 2.939 respectively, and a $p$ value of $1.19 \cdot 10^{-4}$ and $4.47 \cdot 10^{-4}$. A locus on the long arm of chromosome 20, D20S196 showed a rise in the non-parametric-linkage score (from 1.517 to 2.922) and a corresponding decrease in the $p$ value from 0.04 to $6.5 \cdot 10^{-4}$ when families with lower BMI were analysed alone. Other loci with weaker evidence for linkage were also observed.

Conclusions. Our results suggest that chromosome 9 contains genes involved in the susceptibility to Type II diabetes in an eastern and southeastern Chinese Han population, and chromosome 20 could hide genes linked to Type II diabetes in families with a lower BMI. Other regions could also hide susceptibility genes with minor effects. [Diabetologia (2001) 44: 501-506]

Keywords Type II diabetes, genome-wide scan, linkage analysis, susceptibility, candidate gene.
Type II (non-insulin-dependent) diabetes mellitus is a major health problem in many developed countries. In developing countries, like China, the prevalence of Type II diabetes has statistically significantly increased in recent years, especially along with economic growth. In China, the prevalence has almost tripled within the last 15 years, from $1 \%$ to about $3 \%$ [1-4]. Although many efforts have been made to explain the cause of Type II diabetes, we still do not completely understand its pathogenesis. It is now generally accepted, however, that genetic susceptibil-

Received: 1 August 2000 and in revised form: 18 December 2000

Corresponding author: Dr M. Luo, Shanghai Institute of Endocrinology, 197 Ruijin Road II, Shanghai 200025, China ity plays an important part in the development of Type II diabetes, in addition to environmental influences. Probably, in most cases, a number of genes are involved in the susceptibility to Type II diabetes. In some rare forms of Type II diabetes, such as the maturity onset diabetes of the young (MODY) single mutations have been identified of $H N F-4 \alpha$ in MODY1 [5], Glucokinase in MODY2 [6], HNF-1 $\alpha$ in MODY3 [7], insulin promoter factor-1 in MODY4 [8] and $H N F-1 \beta$ in MODY 5 [9]. Identification of the susceptibility genes for the more common form of Type II diabetes has proved much more difficult. Not only could the phenotype be largely influenced by many environmental factors such as nutrition and life style but the susceptibility to Type II diabetes is also affected by the heterogeneity and ethnic variation of the relevant genes. Recently many researchers 
have used family or sib-pair-based linkage analyses and genome-wide scans to detect loci or chromosome regions that are linked to Type II diabetes and obtained some interesting results. One study found locus D2S125, on chromosome 2q37, to be linked to Type II diabetes in a Mexican-American cohort [10]. Other investigators reported that a locus near D12S1349 on chromosome 12 was linked to Type II diabetes in a cohort of Finnish families with the lowest insulin concentrations [11]. Evidence has been found for a linkage on chromosome 20q12-13.1, which was not caused by MODY1 gene [12]. Other loci on different chromosomes have also been reported to be associated with Type II diabetes [13-18]. These results show that the susceptibility genes could vary considerably between populations. Comparison of data from different ethnic groups will thus add to our understanding of the genetic causes of Type II diabetes. Until now, however, most genome-wide scan data have come from Caucasian or American-Indian populations. There is still very little data from east and south east Asian populations. We report results of a study in search of Type II diabetes susceptibility genes in a Chinese Han population using the genome-wide scan method. Our results show that loci on chromosome 9 and 20 could contain genes that contribute to the susceptibility to Type II diabetes.

\section{Subjects and methods}

Population studied. We studied Hans families with at least two siblings affected by Type II diabetes who attended a diabetic clinic in one of five hospitals in east and south-east China. Only families in which either of the siblings were over 35 years of age at onset of diabetes and with only one parent affected were included in the study. Families with both parents or relatives of both parents affected, or families with parents whose status was not identified were not included. Affected status was defined according to the World Health Organization (WHO) criteria (fasting plasma glucose $>7.8 \mathrm{mmol} / \mathrm{l}$ and/or $>11.1 \mathrm{mmol} / \mathrm{l}$ at $2 \mathrm{~h}$ after a $75 \mathrm{~g}$ glucose load) [19]. Where affected family members were already treated by diet or with a diet combined with hypoglycaemic agents, diagnosis was confirmed by the first OGTT result before the beginning of their treatment. We excluded MODY, Type I (insulin-dependent) diabetes mellitus and maternally inherited diabetes on the basis of personal and family history. Family members with glutamic acid decarboxylase autoantibodies exceeding the normal range were also excluded. Non-diabetic subjects were defined as having a fasting plasma glucose of less than $6.1 \mathrm{mmol} / 1$ and a plasma glucose of less than $7.8 \mathrm{mmol} / \mathrm{l}$ at $2 \mathrm{~h}$ after glucose load. Subjects having fasting plasma glucose between 6.1 and $7.8 \mathrm{mmol} / 1$ or a plasma glucose between 7.8 and $11.1 \mathrm{mmol} / \mathrm{l}$ at $2 \mathrm{~h}$ after a glucose load were not included in the study. Non-diabetic family members younger than 40 years of age were excluded from the study. Informed consent was obtained from all participants. The protocol of the study was approved by the Human Subjects Committee of the Chinese Human Genome Centre.

Genotyping. Genomic DNA was extracted from peripheral blood leucocytes by the standard procedure [20]. Highly poly- morphic microsatellite markers were provided by Perkin-Elmer Biosystem Division (ABI Prism Linkage mapping set version 2, Foster City, Calif., USA) which were packaged in a commercially available reaction kit. Originally, 328 microsatellites provided by LMS2 set were used, but for technical reasons, 48 microsatellites were not amplified in more than $90 \%$ of the subjects. A further 33 microsatellites were excluded because of their low heterogeneity in this population (the heterogeneity provided by Genethon was drawn from a Caucasian population and could be very different in other populations such as the Chinese). All the markers were subdivided into 28 panels following the guidelines of the kit and were amplified using a multiplex PCR reaction with a touch-down algorithm to meet the different annealing temperatures of these markers. Briefly, PCR reactions were carried out in a cocktail of $5 \mathrm{ul}$, including $10 \mathrm{mmol} / 1 \mathrm{TRIS}-\mathrm{HCl}$, pH $8.350 \mathrm{mmol} / \mathrm{l} \mathrm{KCl}, 0.1 \mathrm{mg} /$ $\mathrm{ml}$ gelatin, $3.0 \mathrm{mmol} / \mathrm{l} \mathrm{MgCl}_{2}, 200 \mathrm{umol} / \mathrm{l}$ deoxyribonucleoside triphosphates (dNTPs), $0.25 \mathrm{U}$ Taq polymerase, $1.1 \mathrm{ug} / \mathrm{ml} / \mathrm{Taq}$ Start antibody, $0.5 \mathrm{u} \mathrm{mol} / \mathrm{l}$ each pair of primer and $50 \mathrm{ng}$ genomic DNA. Thermo cycling was done in a Perkin-Elmer 9600 Thermocycler. The PCR condition was: denaturation at $94^{\circ} \mathrm{C}$ for $12 \mathrm{~min}$, followed by 39 cycles, each having denaturation at $94^{\circ} \mathrm{C}$ for $1 \mathrm{~min}$, annealing at $56^{\circ} \mathrm{C}$ for $1 \mathrm{~min}$ and extension at $72^{\circ} \mathrm{C}$ for $1 \mathrm{~min}$, except that in the first 14 cycles, the annealing temperature decreased from $63^{\circ} \mathrm{C}$ to $56^{\circ} \mathrm{C}$ by $0.5^{\circ} \mathrm{C}$ per cycle, the final extension was $10 \mathrm{~min}$. The PCR products were then denatured and loaded on $6 \%$ denatured polyacrylamide gel, and the electrophoresis was done on a 377 fluorescence-based DNA sequencer (Applied Biosystem, Foster City, Calif., USA). Genescan 3.0 and Genotyper 2.1 software (Applied Biosystem) were used for lane tracking and size calculation of all the alleles. All genotypes were verified for Mendelian segregation among pedigree members using PedCheck [21]. Genotypes of each locus were reviewed and scored independently by two observers and retyped in case of discrepancy. The statistical power to detect linkage was evaluated by simulation using the computer program SIMLINK (University of Michigan, Ann Arbor, Mich., USA).

Statistical analyses. Single-point and multi-point non-parametric linkage analyses using GENEHUNTER (Whitehead Institute for Biomedical Research, MIT, Mass., USA), which calculates the non-parametric linkage (NPL) score at each position, comparing the observed IBD sharing among all affected family members with that expected under the null hypothesis of no linkage [22], were carried out. According to the suggested guidelines for interpreting results of linkage analysis in a whole genome scan using a dense map, a $p$ value of $7.4 \cdot 10^{-4}$ or less corresponds to "suggestive" linkage and a $p$ value of $2.2 \cdot 10^{-5}$ or less corresponds to "significant" linkage [22]. Only loci that reached the threshold for suggestive evidence $\left(p \leq 7.4 \cdot 10^{-4}\right)$ for linkage are described in detail.

\section{Results}

A total of 102 families (74 with 2 affected siblings, 18 with 3 affected siblings, 10 with 4 affected siblings), including 282 diabetic patients, were available for genotyping. Among these families, both parents' DNA were available in 35 families, DNA from only 1 parent was available in 31 families and in 36 families DNA was not available from either parent. The clinical characteristics of all subjects studied are shown in Table 1. Non-diabetic subjects were also included in 
Table 1. Clinical characteristics of the subjects studied

\begin{tabular}{lll}
\hline $\begin{array}{l}\text { Clinical } \\
\text { characteristics }\end{array}$ & $\begin{array}{l}\text { Type II diabetic } \\
\text { patients }\end{array}$ & $\begin{array}{l}\text { Non-diabetic } \\
\text { subjects }\end{array}$ \\
\hline $\begin{array}{l}\text { Male/Female } \\
\text { Current age }\end{array}$ & $\begin{array}{l}144 / 138 \\
56.4 \pm 12.2(36-83)\end{array}$ & $57.8 \pm 13.5(40-85)$ \\
$\begin{array}{l}\text { Age at diagnosis } \\
\text { Body mass index } \\
\text { (BMI) }\left(\mathrm{kg} / \mathrm{m}^{2}\right)\end{array}$ & $51.7 \pm 10.9(35-74)$ & \\
$\begin{array}{l}\text { Fasting plasma } \\
\text { glucose }(\mathrm{mmol} / \mathrm{l})\end{array}$ & $12.6 \pm 6.7$ & $22.4 \pm 4.1$ \\
\hline
\end{tabular}

the study if they were siblings of diabetic patients. A total of 247 microsatellite markers were typed, with the mean resolution of $15 \mathrm{cM}$. The largest gap was $41.8 \mathrm{cM}$ on chromosome 6 between D6S276 and D6S460. The average heterogeneity of these loci was 0.72 . Using D20S196 as an indicator which was genotyped twice in 58 families, our genotyping error rate was $1.1 \%$. All the loci with "nominal" evidence for linkage $(p<0.05)$ under non-parametric linkage analyses using GENEHUNTER are shown in Table 2, with the relevant NPL-score and $p$ value. Among these loci, only D9S175 and D9S171 which were 67.8 and $42 \mathrm{cM}$ from the pter of chromosome 9 , reached the threshold of suggestive evidence $\left(p<7.4 \cdot 10^{-4}\right)$ for linkage using non-parametric linkage analyses, with the NPL-score of 3.286 and 2.939 and the corresponding $p$ value of $1.19 \cdot 10^{-4}$ and $4.73 \cdot 10^{-4}$. The multipoint linkage analyses also showed a peak NPL-score of 3.351 and 3.112 at $33.4 \mathrm{cM}$ and $59.2 \mathrm{cM}$ (from D9S288), which locate D9S171 and D9S175, respectively (Fig.1). The rest of the loci listed in Table 2 did not reach the generally accepted threshold of suggestive evidence for linkage but we reported
Table 3. Non-parametric linkage analysis result of D20S196, D9S171 and D9S175 in families with lower BMIs and families with higher BMIs

\begin{tabular}{llllll}
\hline & \multicolumn{2}{l}{ Families with lower BMIs } & & \multicolumn{2}{l}{ Families with higher BMIs } \\
\cline { 2 - 3 } \cline { 5 - 5 } & NPL-score & $p$ value & & NPL-score & $p$ value \\
\hline D20S196 & 2.922 & $6 \cdot 10^{-4}$ & & 0.023 & 0.483 \\
D9S171 & 2.316 & 0.005 & & 2.368 & 0.004 \\
D9S175 & 1.674 & 0.031 & 2.420 & 0.003 \\
\hline
\end{tabular}

these results because of their potential biological interest. We then stratified each family according to the mean BMI of affected family members to see if this intermediate trait contributes to the evidence of linkage. We ranked all the families on the basis of their BMI and partitioned families into lower BMI $(\mathrm{BMI} \leq 23)$ and higher BMI groups $(\mathrm{BMI}>23)$. A total of 33 families with a BMI of less than 23 (range 18.4-23.0, mean 21.8), including 47 independently affected sibpairs, were partitioned into the lower BMI group. Our results show that the lower BMI group yielded a rise in the NPL-score at D20S196 from 1.517 to 2.922 , with a corresponding decrease in the $p$ value from 0.04 to $6.53 \cdot 10^{-4}$ compared with that yielded overall from the families. Families with higher BMIs did not contribute to the evidence for linkage (Fig. 2). As for D9S171 and D9S175, both families with lower and higher BMIs contributed to the evidence for linkage (Table 3), although at D9S175, families with higher BMI yielded an NPL-score and Lodscore more relevant than families with lower BMIs.

Table 2. Loci with a $p$ value of less than 0.05 using non-parametric linkage analyses by GENEHUNTER

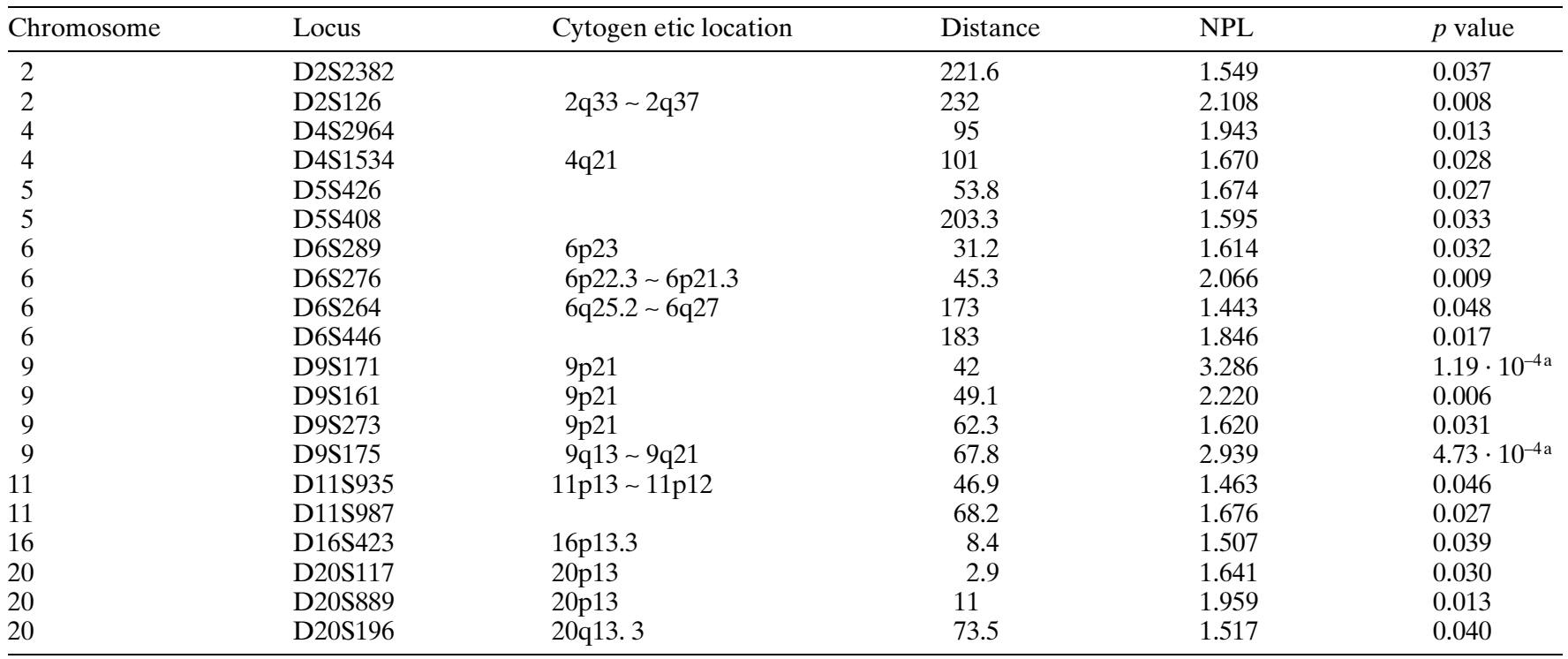

${ }^{a}$ value reached the threshold of suggestive evidence for linkage $\left(\leq 7.4 \cdot 10^{-4}\right)$ 


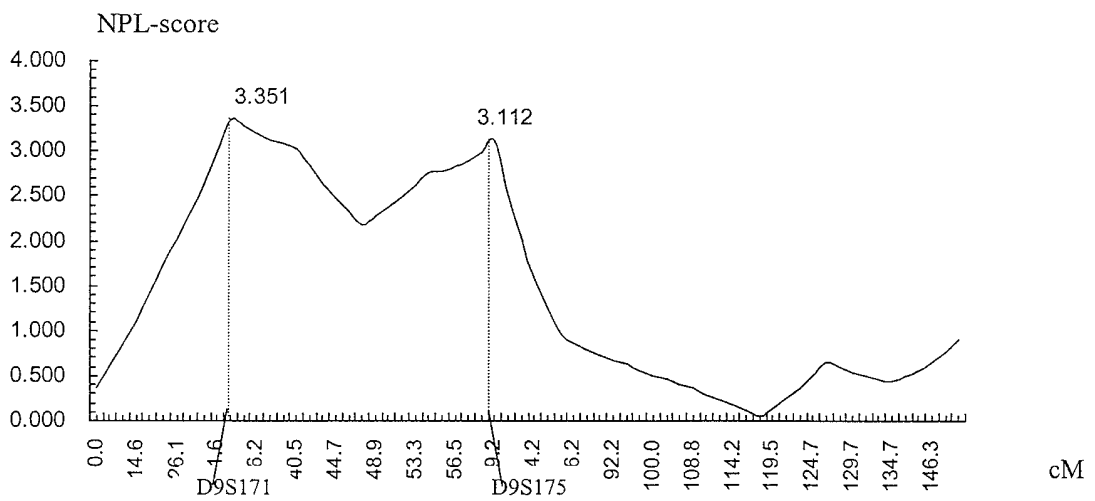

Fig. 1. Multipoint linkage analysis of chromosome 9 showed two peaks of NPL-score at $33.4 \mathrm{cM}$ and $59.2 \mathrm{cM}$ from D9S288

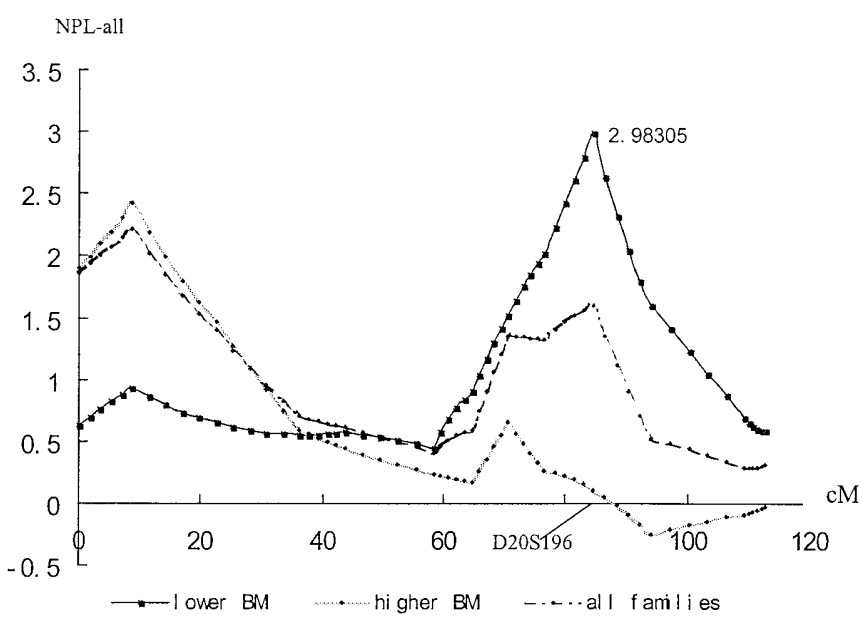

Fig. 2. Multipoint non-parametric linkage analyses of lower BMI family group, higher BMI family group and all families. The result showed a rise in the NPL-score at D20S196 when the lower BMI family group was analysed alone compared with the NPL-score yielded from analyses overall of the families, whereas the NPL-score of D20S196 yielded from the higher BMI group was around 0, indicating that these families did not contribute to the evidence for linkage at this locus. (distance is calculated from D20S117)

\section{Discussion}

Which genes contribute to the susceptibility to the common form of Type II diabetes is still not known. Many studies on different populations have shown evidence for linkage on different regions of a given chromosome or on different chromosomes, implying an ethnic variation in the genetic susceptibility to Type II diabetes. We report the result of a genomewide scan for the Type II diabetes susceptibility genes in a Chinese Han population residing in east and south-east China using non-parametric linkage analyses by GENEHUNTER. Our study suggests evidence for linkage of D9S171 and D9S175 on chromosome 9 with Type II diabetes. These two loci were 42 $\mathrm{cM}$ and $67.8 \mathrm{cM}$, respectively, from pter of chromo- some 9, according to the genetic map of Genethon. One study on a prediabetic population of Pima Indians provided evidence that $9 \mathrm{q} 21$, a region that contains D9S903 (69.3 cM) and D9S1120 (76.1 cM), is linked to fasting and 2-h OGTT insulin concentration [18]. This region is very close to D9S175 which also mapped to $9 \mathrm{q} 21(59 \mathrm{cM})$ in a cytogenetic map. Recently, it has been reported that a region on chromosome 9 (9p13-q21) is linked to Type II diabetes in families from the Botnia region in Finland and almost the same chromosome region (9p12-9q12) linked to the metabolic syndrome [24]. This region is very close to that reported in this study. The D9S1874 locus, with peak NPL reported in the Botnia study was only $8.9 \mathrm{cM}$ to D9S175 according to the genetic map of Genethon.This region contains an important candidate gene: the $X 25$ gene, which, located on chromosome 9q13-21, encodes frataxin, the mitochondrial protein. A decreased expression of this protein will cause Friedreich's ataxia, a common hereditary disease, transmitted in an autosomal recessive mode. This disease is frequently associated with disturbances of glucose metabolism. Homozygous expansion of an intronic GAA repeat in the first intron on X25 inhibits frataxin expression and is associated with clinical manifestations of the disease [25]. Recently, investigators found that intermediate expansions (10 to 36 repeats), which are longer than normal but not sufficient for the appearance of the ataxia phenotype, were associated with Type II diabetes $(p<0.001)[26]$. In two other studies, the association of intermediate expansions of the GAA repeat in the frataxin gene with Type II diabetes was, however, not found [27, 28].

Another finding of our study is a rise of Lod-score and NPL of D20S196 after stratification of families according to the average BMI of the affected family members. The families with the lowest BMIs showed stronger evidence for linkage at D20S196 whereas the rest of the families did not contribute to linkage. In another study stratification of families on the basis of the insulin secretion response unmasked a locus (D12S1394) on chromosome $12 \mathrm{q}$ which showed no evidence for linkage when all the families were analysed together but a suggestive evidence for linkage 
was found when the families in the quartile with the lowest insulin concentrations were analysed alone [11]. This result showed that stratification of families could in some cases dissect heterogeneous families with complex diseases like Type II diabetes into some more homogeneous groups of families, thus increasing the power to detect linkage. Because of the great variation in blood glucose concentration, duration of disease and modality of treatment, which could greatly disturb the insulin response to glucose loading, we did not use the insulin response as an indicator to rank families but rather chose BMI, which is less variable, as the indicator for partitioning families into lower and higher BMI groups. The reason we used $23 \mathrm{~kg} / \mathrm{m}^{2}$ instead of $25 \mathrm{~kg} / \mathrm{m}^{2}$ as a threshold for partitioning families into lower and higher BMI groups is because in a previous report [29] it was found that about $1 / 8$ of the non-overweight and obese Chinese subjects with BMI $23 \sim 25 \mathrm{~kg} / \mathrm{m}^{2}$ could have metabolic syndrome which could be associated with insulin resistance. We found suggestive evidence in the lower BMI group for D20S196 linkage with Type II diabetes whereas there was no evidence for linkage for families in the higher BMI group. This result indicates that low BMI itself, or some factors associated with low BMI, acts on 20q13.3 and yields linkage of D20S196 whereas factors other than BMI yield linkage of D9S171 and D9S175. Clinically, it has been found that general as well as regional adiposity can be closely related to insulin resistance $[29,30]$. Thus our result suggested that factors other than insulin resistance (possibly deficiency in insulin secretion) could have an action on 20q13.3. At least four other research groups have found evidence for linkage in this region, although the precise locus is somewhat different among these results [12, 14-16]. The $20 \mathrm{q}$ 13.3 location contains many candidate genes, among them the HNF4a (MODY1) gene is the most important. We have screened for the mutation of all the exons and part of the promotor region of this gene in families with higher NPL-score at D20S196, but we did not find any mutation in exons and promotor regions (data not shown) in these families. Therefore, $H N F 4 \alpha$ is not likely to be the susceptibility gene for families analysed in this study. Other important candidate genes in the 20q13.3 location include: The PLCG1 gene, encoding an intracellular second messenger involved in signal transduction pathways [31, 32]; the CCAAT/enhancer binding protein $\beta$ gene $(C /$ $E B P-\beta)$, encoding a transcription factor that regulates cAMP-induced expression of the PCK-1 gene in the liver $[33,34]$ and the agouti signalling protein $(A S P)$; mutation of the murine agouti gene is associated with obesity-related Type II diabetes [35]. In conclusion, using a genome-wide scan method, we have found suggestive evidence for linkage with Type II diabetes on chromosome 9 and suggestive evidence for linkage on the long arm of chromosome 20 in diabetic families with lower BMIs. In addition loci with weaker evidence for linkage on other chromosomes were also observed in this study.

Acknowledgements. This study was supported by grants of the "Chinese High Tech Program (863)" Z19-01-02-02 and the "National Key Program on Basic Research (973)" G1998051002 from the Ministry of Science and Technology, People's Republic of China.We are indebted to Professor Zhu Chen (Chinese National Human Genome Center at Shanghai, People's Republic of China) for his continuing support and help. Our thanks are also given to Doctor Wang Qinqin, Zuo Xiangshen, Yu Zhongqin, He Haiping and Doctor Yang Minggong, who recruited the families for the study. We also thank Sun Weihua, Dai Men, Jiang Lin, Yang Jian, Zhang Di, Chen Qinda and Liu Yun for their technical support and all the patients and their families for their cooperation in this study.

\section{References}

1. Shanghai Diabetes Study Coorperation Group (1980) The investigation report of diabetes in a population of 100,000 in Shanghai region. National Medical Journal of China 60: 323-329

2. Investigation subgroup of Chinese Diabetes Study Coorperation Group (1981) The investigation report of diabetes in a population of 300,000 in 14 provinces of China. Chinese Journal of Internal Medicine 20: 678-683

3. Yuan SY, Zhu LX, Hu HY, et al. (1997) A screening survey of diabetes mellitus in a population of 20682 and of OGTT in a population of 1566 in Beijing district. Chinese Journal of Endocrinology and Metabolism 13: 69-72

4. Yang WY, Liu J, Pan XR (1995) A brief report of the second meeting of the national-wide coorperation in the fiveyear prevention and treatment of diabetes. Chinese Journal of Endocrinology and Metabolism 11: 187-188

5. Yamagata K, Furuta H, Oda N et al. (1996) Mutations in the hepatocyte nuclear factor-4-alpha gene in maturity-onset diabetes of the young (MODY1). Nature 384: 458-460

6. Vionnet N, Stoffel M, Takeda J et al. (1992) Nonsense mutation in the glucokinase gene causes early-onset non-insulin-dependent diabetes mellitus. Nature 356: 721-722

7. Yamagata K, Oda N, Kalsaki PJ et al. (1996) Mutations in the hepatocyte nuclear factor-1-alpha gene in maturity-onset diabetes of the young (MODY3). Nature 384: 455-457

8. Stoffers DA, Ferrer J, Clarke WL, Habener JF (1997) Early-onset type-II diabetes mellitus (MODY4) linked to IPF1. Nat Genet 17: 138-141

9. Horikawa Y, Iwasaki N, Hara M et al. (1997) Mutation in hepatocyte nuclear factor-1-beta gene (TCF2) associated with MODY. Nat Genet 17: 384-385

10. Hanis CL, Boerwinkle E, Chakraborty R et al. (1996) A Genome-wide Search for Human Non-Insulin-Dependant (Type II) Diabetes Genes Reveals a Major Susceptibility Locus on Chromosome 2. Nat. Genet 13: 161-166

11. Mahtani MM, Widen E, Lehto M, et al. (1996) Mapping a gene for Type II diabetes associated with an insulin secretion defect by a genome scan in Finnish families. Nat Genet 14: 90-94

12. Ji L, Malecki M, Warram JH et al. (1997) New susceptibility locus for NIDDM is localized to human chromosome 20 q. Diabetes 46: 876-881

13. Steven CE, Michael DH, Kui T et al. (1999) A GenomeWide Search for Type II Diabetes Susceptibility Genes in Utah Caucasians. Diabetes 48: 1175-1182 
14. Bowden DW, Sale M, Howard TD et al. (1997) Linkage of Genetic Markers on Human Chromosome 20 and 12 to NIDDM. Diabetes 46: 882-886

15. Zouali H, Hani EH, Phillipi A et al. (1997) A Susceptibility Locus for Early-Onset Non-Insulin Dependant (Type II) Diabetes Mellitus Maps to Chromosome 20q, Proximal to the Phosphoenolpyruvate carboxykinase gene. Human Mol Genetic 6: 1401-1408

16. Ghosh S, Watanabe RM, Hauser ER et al. (1999) Type II Diabetes: Evidence for Linkage on Chromosome 20 in 716 Finnish Affected Sib Pairs. Proc Natl Acad Sci USA 96: 2198-2203

17. Hegele RA, Sun F, Harris SB et al. (1999) Genome-wide scanning for type 2 diabetes susceptibility in Canadian Oji-Cree, using 190 microsatellite markers. J Hum Genet 44: $10-14$

18. Richard EP, Bruce DT, Michal P et al. (1998)An Autosomal Genomic Scan for Loci Linked to Prediabetic Phenotypes in Pima Indians. J Clin Invest 101: 1757-1764

19. WHO Expert Committee on Diabetes Mellitus (1980) Second Report, Technical report series No 646, World Health Organization, Geneva

20. Sambrook J, Fritsch EF, Maniatis T (1989) Molecular Cloning: A Laboratory Manual, $2^{\text {nd }}$ edn. Cold Spring Harbor Laboratory Press, Cold Spring Harbor

21. O'Connell JR, Weeks DE (1997) PedCheck: a program for identifying marker typing incompatibilites in linkage analysis. Am J Hum Genet 10: A288

22. Kruglyak L, Daly MJ, Reeve-Daly MP, Lander ES (1996) Parametric and Nonparametric Linkage Analysis: A Unified Multipoint Approach. Am J Hum Genet 58: 1347-1363

23. Lander ES, Kreglyak L (1995) Genetic dissection of complex traits: guidelines for interpreting and reporting linkage results. Nat Genet 11: 241-247

24. Wieslander J, Almgren P, Lindgren C et al. (2000) A geneome-wide search for susceptibility loci to the metabolic syndrome in the Botnia study. 36th Annual meeting of the european association for the study of diabetes: Diabetologia 43 [Suppl 1]: A 87 (Abstract 343)

25. Campuzano V, Montermini L, Molto MD et al. (1996) Friedreich's ataxia: autosomal recessive disease caused by an intronic GAA triplet repeat expansion. Science 271: $1423-1427$
26. Ristow M, Giannakidou E, Hebinck J, et al. (1998) An association between type 2 diabetes mellitus (NIDDM) and a GAA Trinucleotide Repeat Polymorphism in the Frataxin (Griedreich Ataxia) Gene. Diabetes 47: 851-854

27. Dalgaard LT, Hansen T, Urhammer SA, Clausen JO, Eiberg H, Pedersen O (1999) Intermediate expansions of a GAA repeat in the frataxin gene are not associated with type 2 diabetes or altered glucose-induced beta-cell function in Danish Caucasians. Diabetes 48: 914-917

28. Hart LM, Ruige JB, Dekker JM, Stehouwer CD, Maassen JA, Heine RJ (1999) Altered beta-cell characteristics in impaired glucose tolerant carriers of a GAA trinucleotide repeat polymorphism in the frataxin gene. Diabetes 48: 924-926

29. Xiang KS, Jia WP, Lu JX et al. (2000) The impact of obesity on metabolic syndrome in Chinese aged over 40 in Shanghai, China. Chin J Intern Med 39: 224-233

30. Campbell PJ, Carlson MG (1993) Impact of obesity on insulin action in NIDDM. Diabetes 42: 405-410

31. Bristol A, Hall SM, Kriz RW et al. (1988) Phospholipase C148: chromosomal location and deletion mapping of functional domains. Cold Spring Harb Symp Quant Biol 53: 915-920

32. Rothschild CB, Akots G, Fajans SS, Bowden DW (1992) A microsatellite polymorphism associated with the PLC1 (phospholipase C) locus: identification, mapping, and linkage to the MODY locus on chromosome 20. Genomics 13: $560-564$

33. Hendricks-Taylor RL, Bachinski LL, Siciliano MJ et al. (1992) The CCAAT/enhancer binding protein a (E/EBPa) gene (CEBPA) maps to human chromosome 19q13.1 and the related nuclear factor NF-IL6 $(\mathrm{C} / \mathrm{EBPb})$ gene $(\mathrm{CE}$ $\mathrm{BPB}$ ) maps to human chromosome 20q13.1. Genomics 14: 12-17

34. Park EA, Gurney AL, Nizielske SE et al. (1993) Relative roles of CCAAT/enhancer-binding protein beta and cAMP regulatory element-binding protein in controlling transcription of the gene for phosphoenolpyruvate carboxykinase (GTP). J Biol Chem 268: 613-619

35. Klebig ML, Wilkinson JE, Geisler JG, Woychik RP (1995) Ectopic expression of the agouti gene in transgenic mice causes obesity, features of type II diabetes, and yellow fur. Proc Natl Acad Sci USA 92: 4728-4732 